\title{
Depression among elderly living in Briddashram (old age home)
}

\author{
Hom Nath Chalise \\ Asian College for Advance Studies, Purbanchal University, Satdobato, Lalitpur, Nepal; \\ chalisehkpp@gmail.com
}

Received 11 September 2013; revised 11 October 2013; accepted 18 October 2013

Copyright (c) 2014 Hom Nath Chalise. This is an open access article distributed under the Creative Commons Attribution License, which permits unrestricted use, distribution, and reproduction in any medium, provided the original work is properly cited. In accordance of the Creative Commons Attribution License all Copyrights (C) 2014 are reserved for SCIRP and the owner of the intellectual property Hom Nath Chalise. All Copyright (C) 2014 are guarded by law and by SCIRP as a guardian.

\section{ABSTRACT}

Introduction: Depression is a common public health issue with the increasing life expectancy worldwide and depression is associated with morbidity as well as disability among the elderly. There are very few studies related with depression among elderly from developing countries. Objective: The purpose of this study was to assess the prevalence of depression and its correlates among the elderly living in Briddashram (old age home). Methods: This is a cross-sectional study carried out in 2012. Data were collected by face-to-face interview using short version of Geriatric Depression Scale. The data were analyzed using percentage, mean, simple correlation and regression. Results: The subjects $(N=185)$ were elderly aged 60 years and above living in Devghat area, Nepal. Mean age of the subjects was $73.67( \pm 3.23)$ years old and $51 \%$ were male. $94 \%$ elderly belong to Khas ethnicity. Nearly one third (31\%) elderly were from nuclear family back ground, $25 \%$ were married, and only $18 \%$ elderly were literate. Majority of the elderly (93\%) had health problems and self reported health shows $86 \%$ elderly reported their health fair. This study shows mean functional disability score was $2.53( \pm 2.05)$. Finding shows the prevalence of depression was $\mathbf{5 7 . 8 \%}$. Among them $46.7 \%$ had mild, $8.9 \%$ had moderate and $2.2 \%$ had severe depression. A statistically significant correlation was found between feelings of depression and age, sex, previous family type, ethnicity, feeling of loneliness and instrumental activities of daily living. Regression analysis shows that being women, feeling of loneliness and higher the dependency in IADL were predictors of depression. Conclusion: This study indicates that many elderly living in the Briddashram are suffering from depression. There should be some interruption from the concerned authorities so that depression can be reduced which will support to the well-being and quality of life of elderly.

\section{KEYWORDS}
Depression; Elderly; Briddashram; Old Age Home; Nepal

\section{BACKGROUND}

Old age is usually discussed in connection with the different types of problems encountered by the aged and the welfare measures associated with providing them a better quality of life. It has been observed that physical diseases, psychological illness and adjustment problems are quite common during this phase of life. People in general are approacensive and speak about the difficulties that they face during the fag end of their lives. In elderly physical changes include wrinkling of skin, stopped posture, flabbiness of muscles, decreased vision and hearing, a decreased efficiency of cardiovascular system. The theme of this age period is loss, which may be identified like loss of physical abilities, loss of intellectual rocesses, loss of work role and occupational identification (Retirement), loss of intimate ties, such as death of spouse, friends and other a acquaintances [1].

Depression is common in the elderly and is a major public health problem. The WHO (2005) also emphasizes that depression, which is the fourth most common illness, can lead to physical, emotional, social and economic problems [2]. The prevalence rate of depression varies worldwide and their prevalence rates range be- 
tween $10 \%$ and 55\% [3-6]. A study shows the depression ranges from $34.6 \%$ to $77.5 \%$ in old age home [7]. Depression in late life is associated with significant morbidity, including deficits in a range of cognitive functions and considerable influence on functional impairment, disability [8], decreased quality of life, and has a negative effect on the body's recovery from illness, increases the rate of suicide, increases use of health care services and expenses and can result in early death and disturbance in the general state of wellness $[9,10]$.

Depressive symptoms are associated with greater impairment and decreased quality of life among patients with coexisting chronic illnesses, such as emphysema, cancer, and diabetes. When depression coexists with other medical conditions, the resulting disability appears to be additive [11]. However, even in older adults without a disability, depression significantly increases the risk for subsequent incident ADL and mobility disability [12]. Further, studies show that "depressed persons, including depressed elderly persons, use two to three times as many medical services as people who are not depressed [11]." Other studies have estimated that "elderly persons with depressive symptoms accrued 50\% higher healthcare costs from more frequent use of medical services" than do other older adults not suffering from depression [13].

Unfortunately, depression is particularly problematic in developing countries, where data on the prevalence and scope of the disease as well as the resources to address it are sorely lacking. Cost-effective interventions are available, but do not often reach those who need them because of a number of overwhelming challenges in low-resource settings-lack of facilities and trained mental health personnel, questions about effective population-based screening, and the general stigma surrounding mental disorders [14].

Although Nepal is one of the least developed countries in the world, elderly is increasing rapidly both in absolute number and proportion. According to latest census of 2011, the proportion of elderly 60 years and above reached 8.2 percent of total population. But the government has not given priority to identify the problems of the elderly through research and to implement existing senior citizen act for the wellbeing of elderly. Depression among elderly in Nepal has not been well studied. Little is known about the true rates of depression, its correlates and predictors. There is no exact figure reported for the incidence of depression among Nepali elderly. However, a study was performed among elderly patients attending the outpatient department of a hospital in 2006 showed that the incidence of depression was as high as $53.2 \%$ [6].

In Nepal traditionally Briddashram (old age home) is designed only for the elderly who do not have their children to take care of them. And many of these Briddashram are located in the religious places. But recently with the effect of modernization, urbanization, nucleation of family, migration of yourths to urban area, and foreign countries those people who prefer to live in the Briddashram are increasing. But, due to limited capacity and limited number of Briddashram, community people have started to open Briddashram in the different parts of the country.

The aim of this study is to determine the prevalence of depression and its predictors among elderly living in Briddashram. The rationale for this study is the widely held impression that depression is common in elderly and results in more days of disability than chronic medical conditions such as heart disease, hypertension and diabetes [15].

\section{METHODS}

\section{Study Site and Sample}

This is a cross-sectional study carried out in Devghat, which is one of the holiest places in the Nepal for Hindus. The area is surrounded by the rivers from all four sides linked by a suspension bridge from the main entry. It has wonderful panoramic view and is believed that gods come to take a dip in the holy confluence. There were some Briddashram and Trust providing shelter to older people as well as some people is living in their own residence. For the purpose of this study we included elderly either living or dependent in Briddashram (old age home) or in the trust, namely: Devghat Area Development Committee Briddashram, NRN Briddashram, Rotary Karunalaya, Sri Galeshor Ashram Trust. There were respectively 34, 58, 32 and 150 elderly living in the above Briddashram or Trust. All the elderly living in these four residences were approached to include in this study. Elderly people who had been staying for at least six month were considered eligible. Those suffering from severe mental and physical illness e.g., psychosis, dementia, hearing impairment, and dumbness were excluded. This study was carried out in two month MarchAril of 2012. During this time we approached 191 eligible elderly but questionnaire was completed with 180 elderly only.

The study protocol was approved by the Research Committee of Asian College for Advance Studies, Lalitpur. A request letter for the permission of data collection was submitted to each institution of Devghat. Verbal consent was obtained after explaining the purpose and method of study. The inmates were explained the purpose of interview and oral informed consent was obtained from all participants before interviews [16].

To ensure the questionnaire's quality and sensitivity Geriatric Depression Scale Short Form (GDS (SF = 15)) 
[17] was translated into Nepali from English and then back translated into English by English language teachers proficient in both languages. Different people conducted the back translation. A pilot study of 15 respondents from the non-study area was conducted to identify potential problems with the questionnaire.

\section{MEASUREMENTS}

\subsection{Dependent Variable}

In this study Depression was dependent variable and measured using GDS ( $\mathrm{SF}=15)$ [17]. GDS $(\mathrm{SF}=15)$ was the short version of widely used Geriatric Depression Scale (GDS) [18]. Studies from the United States, United Kingdom and many Asian countries have shown that the GDS can be employed with different cultures and ethnicities. Further, a previous study carried out in Nepal has already proved GDS was a reliable tool to screen depression in the Nepalese patients [6]. Reliability of GDS measured through Cronbach's Alpha $=0.865$ shows quite high in this study. Many studies have proved very high correlation between GDS and GDS (SF = 15) [19]. GDS $(\mathrm{SF}=15)$ had 15 statements with yes or no response. Theoretically sum of the response ranged from 0 to 15 . For the interpretation of situation of depression, Sheikh \& Yesavage (1986) have suggested score 0 - 4 as normal, 5 - 8 as mild depression, $9-12$ as moderate depression and 13 - 15 as severe depression [17].

\subsection{Independent Variables}

Sex was measured as a dichotomous variable with male coded " 1 " and female " 2 ". Age was measured as a continuous variable. Previous family type was a dichotomous variable of "nuclear" coded "1"and "joint" coded " 2 ". Marital status was dichotomized "married" coded " 1 " and "widow or widower" coded "2". Widow or widower includes unmarried, divorced and separated. The proportion of unmarried divorced and separated was very low. Educational level was categorized as literate "1" and illiterate (who can not read and write) "2". Feeling of loneliness was measured as "yes (often and some time)" coded " 1 ", "no" coded as 3.

Functional capabilities of older adults were measured using five items (traveling by public transportation, shopping for groceries, preparing meals, doing light house work, and taking medicine) from the seven item IADL scale [20]. Two items from the IADL scale, use of the telephone (look up the number, dial and answer) and management of money (write checks and pay bills) were not included in the final questionnaire because these were not applicable for the majority of Nepalese elderly $[16,21,22]$ because they cannot read number and dial the telephone and even write the name also. Responses were categorized as "unable to do at all", "with some difficul- ty/need some help" and "without help”. For the present study, responses were coded as "Self" coded as " 1 " and "with some difficulty /need some help" coded as " 2 " and "cannot do at all-3". To calculate the level of functional disability the sum of the above five items was added and measured as a continuous variable. Higher the value of IADL score indicates the higher the dependency. Internal consistency reliability of IADL in this study measured through Cronbach's alpha 0.908 shows quite satisfactory.

\section{RESULTS}

The distribution of social, demographic and healthrelated characteristics of the respondents of this study is given in Table 1. Subjects ranged in age from 60 to 95 years with a mean $( \pm S D)$ age of $73.67( \pm 3.23)$ years. Ninety one (50.6\%) were male, one hundred seventy (94.4\%) were Khas ethnicity, fifty five (30.6\%) were from nuclear family, fourty five $(25.0 \%)$ were married, thirty two (17.8\%) were literate, 92.8 percent had health problems, majority of the subjects reported their health fair (86.1\%), 77.8\% had feeling of loneliness. Mean functional limitation in IADL score was 2.53 .

More than ninety percent (93.9\%) elderly had some health problem recently. Mean functional disability of the elderly was 6.11 ( \pm 2.05$)$. More than fifty percent (50.9) elderly felt loneliness some time, 33 percent often and 15.8 felt loneliness rarely. Average income of the elderly was NRs $10181.82( \pm 2403.05)$ and $61 \%$ elderly spent less time with the family members.

Table 2 shows the situation of depression of the subjects elderly included in this study. For the measurement of Depression GDS (SF = 15) was used. This study found mean depression score of elderly was $5.6( \pm 2.19)$ ranging from 3 to 13 .

Severity of depression is measured on the basis of depression score. This study shows that 42.2 percent elderly had normal depression score, $46.7 \%$ had mild depression, $8.9 \%$ had moderate and $2.2 \%$ had severe depression. From this data we can say that prevalence of depression was $57.8 \%$ in this population. For the further regression analysis depression score was now dichotomized score 0 - 4 no depression and score 5 and above as having depression.

Table 3 shows results of bivariate analysis of depression with selected background variables. Age $(\mathrm{P}=0.001)$, sex $(P=0.001)$, previous family type $(P=0.000)$, type of ethnicity $(\mathrm{P}=0.000)$, limitations in IADLs $((\mathrm{P}=0.000)$, and feeling of loneliness $(0.000)$ were significantly positively or negatively correlated with depression and were included in logistic regression analyses. Non-significant predictors were removed from the model.

Results of the logistic regression of depression are shown in Table 4. The goodness of fit statistics (Hosmer 
Table 1. Selected background characteristics of elderly living in Briddshram, Devghat, $\mathrm{N}=180$.

\begin{tabular}{cccccc}
\hline Variables & N & $\%$ & Mean & SD $^{\text {a }}$ & Range \\
\hline Sex (male) & 91 & 50.6 & & & \\
Age & & & 73.67 & 3.23 & $60-95$ \\
Ethnicity (Khas) & 170 & 94.4 & & & \\
Previous Family Type (nuclear) & 55 & 30.6 & & & \\
Marital Status (married) & 45 & 25.0 & & & \\
Literacy Status (literate) & 32 & 17.8 & & & \\
Presence of any disease (yes) & 167 & 92.8 & & & \\
Feeling of loneliness (yes) & 140 & 77.8 & & & \\
Self reported health & & & & & \\
Good & 21 & 11.7 & & & \\
Fair & 155 & 86.1 & & & \\
Poor & 4 & 2.2 & & & \\
Living arrangement & & & & & \\
Galeshor Ashram & 68 & 37.8 & & & \\
NRN Bridashram & 52 & 28.9 & & & \\
Rotary Karunalaya & 30 & 16.7 & & & \\
Government Briddashram & 30 & 16.7 & & \\
Problem with IADL & & & 2.53 & 2.05 & $0-9$ \\
\hline
\end{tabular}

${ }^{\mathrm{a}}$ Standard deviation; ${ }^{\mathrm{b}} \mathrm{Higher}$ score indicates worse functional disability.

Tab le 2. Situation of depression in elderly living in Briddashram, Devghat, $\mathrm{N}=165$.

\begin{tabular}{cccccc}
\hline Variables & $\mathrm{N}$ & $\%$ & Mean & SD & Range \\
\hline Sum of GDS & & & 5.6 & 2.19 & $3-13$ \\
Severity of Depression & & & & & \\
Normal & 76 & 42.2 & & & \\
Mild Depression & 84 & 46.7 & & & \\
Moderate Depression & 16 & 8.9 & & & \\
Severe Depression & 4 & 2.2 & & & \\
Total & 180 & 100.0 & & & \\
\hline
\end{tabular}

Table 3. Correlation and bivariate analysis of depression with some socio-demographic and health variables, $\mathrm{N}=165$.

\begin{tabular}{ccc}
\hline Variable & $\begin{array}{c}\text { Spearmans Correlation } \\
\text { Coefficeint ((rs) }\end{array}$ & $\mathrm{P}$ \\
\hline Sex & $0.250^{* * *}$ & 0.001 \\
Age & $0.236^{* *}$ & 0.001 \\
Previous family type & $0.272^{* *}$ & 0.000 \\
Type of ethnicity & $0.544^{* *}$ & 0.000 \\
Marital Status & 0.041 & 0.584 \\
Living place & -0.099 & 0.187 \\
Literacy status & 0.082 & 0.271 \\
Having health problem & -0.122 & 0.102 \\
Limitations in IADL & $0.492^{* *}$ & 0.000 \\
Feeling of loneliness & $0.443^{* *}$ & 0.000 \\
\hline
\end{tabular}

${ }^{* *}$ Correlation is significant at the 0.01 level (2-tailed). ${ }^{*}$ Correlation is significant at the 0.05 level (2-tailed).
Tab le 4. Logistic regression of depression, $\mathrm{N}=165$.

\begin{tabular}{|c|c|c|c|c|c|c|}
\hline \multirow{2}{*}{ Variables ${ }^{*}$} & \multirow{2}{*}{$\begin{array}{l}\text { Regression } \\
\text { Coefficients } \\
\text { (B) }\end{array}$} & \multirow{2}{*}{$\begin{array}{l}\text { Standard } \\
\text { Error }\end{array}$} & \multirow{2}{*}{$\begin{array}{l}\text { Odds } \\
\text { Ratio }\end{array}$} & \multicolumn{2}{|c|}{$95 \%$ CI } & \multirow{2}{*}{$\mathrm{P}$} \\
\hline & & & & Lower & Upper & \\
\hline $\begin{array}{l}\text { Limitation } \\
\text { in IADL }\end{array}$ & 0.452 & 0.143 & 1.671 & 1.21 & 2.312 & 0.000 \\
\hline $\begin{array}{l}\text { Feeling of } \\
\text { loneliness }\end{array}$ & 0.399 & 0.112 & 2.008 & 0.997 & 7.074 & 0.029 \\
\hline \multirow[t]{3}{*}{ Sex } & 0.341 & 0.213 & 1.371 & 1.002 & 2.103 & 0.021 \\
\hline & \multicolumn{5}{|c|}{ Hosmer and Lemeshow's Test $\mathrm{P}=0.352$} & \\
\hline & \multicolumn{5}{|c|}{-2 Log likelihood = 140.341} & \\
\hline
\end{tabular}

OR = Odds Ratio, CI = Confidence Interval; ${ }^{*}$ Only significant variables are shown from the variables entered: age, sex, previous family type, ethnicity, limitations in IADLs, feeling of loneliness.

and Lemeshow's test $\mathrm{P}=0.352$ and -2 Log likelihood $=$ 140.341) indicated a satisfactory fit for the model. Significant predictors of depression in the model were limitation in IADL $(\mathrm{OR}=1.671,95 \% \mathrm{CI} 1.21-2.312, \mathrm{P}=$ $0.005)$, being woman $(\mathrm{OR}=1.371,95 \% \mathrm{CI} 1.002-2.103$, $\mathrm{P}=0.041)$ and feeling of loneliness $(\mathrm{OR}=2.008,95 \%$ CI $0.997-7.074, \mathrm{P}=0.000$ ).

\section{DISCUSSION AND CONCLUSIONS}

Depression is recognized as an important public health and social issue, predicting, among other things, low quality of life among older adults. There are very little studies from least developed countries about the situation of depression among the elderly. The primary purpose of the present study was to examine the prevalence of depression and correlates of depression in older adults living Biddashram (Old age home).

This study found the prevalence of depression measured through GDS (SF = 15) among Briddashram living Nepalese elderly was 57.8 percentages. This study found mean depression score of elderly was $5.6( \pm 2.19)$ ranging from 3 to 13. Similar to his study, a recent study carried out in elderly living in old age home in India shows prevalence of depression was $63.8 \%$ and mean Geriatric Depression Scale score was $6.86( \pm 0.17)$ [23]. This shows the prevalence of depression was quite high. Further another recent study by Sethi et al. (2013) also found elderly subjects living in Old age home are more affected in terms of depression as compared to community dwelling elder subjects [24]. Reason for higher prevalence might be that the institutionalized elderly feel lonelier and depressed as they lack social network support and do not feel "the level of kinship" felt by non-institutionlized aged.

Impaired in instrumental activities of daily living (IADL) is an expression of functional dependence and one of the most commonly used measures in assessing health in old age. This study found having functional disabilities in IADLs is an important predictor of loneli- 
ness. This findings is consistent with many other studies across the world [25-27]. Symptoms of depression may cause or exacerbate physical disability in older individuals and may do so to a greater extent than other common chronic diseases such as hypertension, arthritis, heart disease, and diabetes [11]. Many researchers see a mutual causality between depression and disability such that "illness and physical disability cause depression, and also that depression leads to illness and physical decline, either because of behavioral factors (e.g., failure to take care of personal health) or biological factors (e.g., improper functioning of the immune or endocrine system) [28].”

This study found being woman was another predictor of depression. This finding is consistent with many other studies [29-31]. Loneliness was also another predictor of depression in the elderly living in Briddashram. This study finding was also consistent with previous study from Nepal showing loneliness was quite high among Nepalese woman elderly compared to male [16] and loneliness was found significantly correlated with depression in this study. There is not any exact reason why depression is high among Nepalese elderly. This may be due to differences in how elderly men and women perceive to answer the scale used to measure the depression. A study carried out by Singh \& Mishra (2009) also found a significant relationship between loneliness and depression [32]. Mohan \& Begum also found positive correlation between depression and loneliness [33].

Although this was a first attempt to study the prevalence of depression in the elderly living in Briddashram, several limitations of this study should be considered before its generalization. First, it was cross-sectional in nature; thus, the results did not establish causal relationships for the study variables. Second, the data covered Briddashram of only one area. Third, the validity of the GDS was not examined in this study, although the previous study reported GDS is a valid measure to meaure the depression in Nepali elderly.

In spite of the limitations, the findings of this study suggest that feelings of depression are a serious problem among Nepalese older adults living in Devghat area which is considered a sacred place for Hindus. Further research using qualitative method also needed to identify risk factors of increasing depression among the elderly. This may contribute to the empowerment of the elderly and, thus, enhance their quality of life in the future.

\section{CONFLICT OF INTEREST}

There is no conflict of interest regarding the publication of this manuscript.

\section{REFERENCES}

[1] Dhara, R.D. and Jogsan, Y.A. (2013) Depression and psychological well-being in old age. Journal of Psychology \& Psychotherapy, 3, 117.

http://dx.doi.org/10.4172/2161-0487.1000117

[2] World Health Organization (WHO) (2005). World Health Report, 2005. http://www.who.int/whr/2005/annexes-en.pdf

[3] Sherina, M.S., Rampal, L. and Mustaqim, A. (2004). The prevalence of depression among the elderly in Sepang, Selangor. Medical Journal of Malaysia, 59, 45-49.

[4] Chi, I., et al. (2005). Prevalence of depression and its correlates in Hong Kong's Chinese older adults. American Journal of Geriatric Psychiatry, 13, 409-416.

[5] Tsai, Y.F., Yeh, S.H. and Tsai, H.H. (2005). Prevalence and risk factors for depressive symptoms among community-dwelling elders in Taiwan. International Journal of Geriatric Psychiatry, 20, 1097-1102.

http://dx.doi.org/10.1002/gps.1413

[6] Khattri, J.B. and Nepal, M.K. (2006). Study of depression among geriatric population in Nepal. Nepal Medical College Journal, 8, 220-223.

[7] Weyerer, S., Mann, A.H. and Ames, D. (1995) Prevalence of depression and dementia in residents of old age homes in Mannheim and Camden (London). Zeitschrift für Gerontologie und Geriatrie, 28, 169-178.

[8] Tam, C.W.C. and Chiu, H.F.K. (2011) Depression and suicide in the elderly. The Hong Kong Medial Diary, Medical Bulletin, 16, 13-15.

[9] Steffens, D.C., Skoog, I., Norton, M.C., Hart, A.D., Tschanz, J.T., Plassman, B.L., Wyse, B.W., Welsh-Bohmer, K.A. and Breitner, J.C.S. (2000) Prevalence of depression and its treatment in an elderly population: The Cache Country Study. Archives of General Psychiatry, 57, 601-607. http://dx.doi.org/10.1001/archpsyc.57.6.601

[10] Serby, M. and Yu, M. (2003) Overview: Depression in the elderly. Mount Sinai Journal of Medicine, 70, 38-44.

[11] Langa, K.M., Valenstein, M.A., Fendrick, A.M., et al. (2004) Extent and cost of informal caregiving for older Americans with symptoms of depression. American Journal of Psychology, 161, 857-863.

[12] Penninx, B.W.J.H., Leveille, S., Ferrucci, L., et al. (1999) Exploring the effect of depression on physical disability: Longitudinal evidence from the established populations for epidemiologic studies of the elderly. American Journal of Public Health, 89, 1346-1352. http://dx.doi.org/10.2105/AJPH.89.9.1346

[13] Katon, W.J. (2008) The comorbidity of diabetes mellitus and depression. The American Journal of Medicine, 121, S8-S15. http://dx.doi.org/10.1016/j.amjmed.2008.09.008

[14] Worley, H. (2006) Depression: A leading contributor to global burden of disease. www.prb.com http://www.coa.gov.ph/gad/articles/depression_062006.ht $\underline{\mathrm{m}}$

[15] Williams, R.A. and Strasser, P.B. (1999) Depression in the work place. Impact on employees. AAOHN Journal, 47, 526-537.

[16] Chalise, H.N., Saito, T., Takahashi, M. and Kai, I. (2007) Relationship specialization amongst sources and receivers of social support and its correlations with loneliness and 
subjective well-being: A cross-sectional study of Nepalese older adults. Archives of Gerontology and Geriatrics, 44, 299-314. http://dx.doi.org/10.1016/j.archger.2006.07.001

[17] Sheikh, J.I. and Yesavage, J.A. (1986) Geriatric Depression Scale (GDS): Recent evidence and development of a shorter version. Clinical Gerontology, 5, 165-173.

[18] Yesavage, J., Brink, T., Rose, T., et al. (1983) Development and validation of a geriatric depression screening scale. Journal of Psychiatric Research, 17, 37-49. http://dx.doi.org/10.1016/0022-3956(82)90033-4

[19] van Marwijk, H.W., Wallace, P, de Bock, G.H., Hermans, J., Kaptein, A.A. and Mulder, J.D. (1995) Evaluation of the feasibility, reliability and diagnostic value of shortened versions of the geriatric depression scale. British Journal of General Practice, 45, 195-199.

[20] Lawton, M.P. and Brody, E.M. (1969) Assessment of older people: self-maintaining and instrumental activities of daily living. Gerontologist, 9, 179-186. http://dx.doi.org/10.1093/geront/9.3_Part_1.179

[21] Chalise, H.N., Saito, T. and Kai, I. (2008) Situation of functional disability in activities of daily living and instrumental activities of daily living among Nepalese Newar elderly. Public Health, 122, 394-396. http://dx.doi.org/10.1016/j.puhe.2007.07.015

[22] Chalise, H.N., Saito, T. and Kai, I. (2010) Social support and its correlation with loneliness: A cross-cultural study of Nepalese older adults. International Journal of Aging and Human Development, 71, 115-137. http://dx.doi.org/10.2190/AG.71.2.b

[23] Narkhede, V., Likhar, S. and Rana, A. (2012) A study on depression in elderly inmates living in old age homes in Gujarat. Indian Journal of Research and Reports in Medical Sciences, 2, 21-23.

[24] Sethi, V., Verma, V. and Singh, U. (2013) Impact of ageing on depression and activities of daily livings in normal elderly subjects living in old age homes and communities of Kanpr, U.P. International Journal of Medical Research \& Health Sciences, 2, 243-249. http://dx.doi.org/10.5958/j.2319-5886.2.2.028
[25] Imran, A., Azidah, A.K., Asrenee, A.R. and Rosediani, M. (2009) Prevalence of depression and its associated factors among elderly patients in outpatient clinic of Universiti Sains Malaysia Hospital. Medical Journal of Malaysia, 64, 134-139.

[26] Biderman, A., Cwikel, J., Fried, A.V. and Galinsky, D. (2002) Depression and falls among community dwelling elderly people: A search for common risk factors. Journal of Epidemiology \& Community Health, 56, 631-636. http://dx.doi.org/10.1136/jech.56.8.631

[27] Penninx, B.W.J.H., Guralnik, J.M., Ferrucci, L., Simonsick, E.M., Deeg, D.J.H. and Wallace, R.B. (1998) Depressive symptoms and physical decline in communitydwelling older persons. The Journal of the American Medical Association, 279, 1720-1726. http://dx.doi.org/10.1001/jama.279.21.1720

[28] Penninx, B.W.J.H., Deeg, D.J.H., van Eijk, J.T.M., et al. (2000) Changes in depression and physical decline in older adults: A longitudinal perspective. Journal of Affective Disorders, 61, 1-12. http://dx.doi.org/10.1016/S0165-0327(00)00152-X

[29] Maulik, S. and Dasgupta, A. (2012) Depression and its determinants in the rural elderly of West Bengal-A cross sectional study. International Journal of Biological and Medical Research, 3, 1299-1302.

[30] Taqui, A.M., Itrat, A., Qidwai, W. and Qadri, Z. (2007) Depression in the elderly: Does family system play a role? A cross-sectional study. BMC Psychiatry, 7, 57. http://dx.doi.org/10.1186/1471-244X-7-57

[31] Ariyo, A.A., Hann, M., Tangen, C.M., et al. (2000) Depressive symptoms and risks of coronary heart disease and mortality in elderly Americans. Circulation, 102, 1773-1779.

[32] Singh, A. and Misra, N. (2009) Loneliness, depression and sociability in old age. Industrial Psychiatry Journal, 18, 51-55. http://dx.doi.org/10.4103/0972-6748.57861

[33] Mohanth, N. and Begum, F.A. (2011) Geriateric depression, loneliness and psychological well-being: Roll of age and gender. Indian Journal of Psychology and Mental Health, 5, 53-61. 